\title{
Fusion of the TBL1XR1 and HMGA1 genes in splenic hemangioma with $\mathbf{t}(3 ; 6)(\mathbf{q} 26 ; \mathbf{p} 21)$
}

\author{
IOANNIS PANAGOPOULOS ${ }^{1,2}$, LUDMILA GORUNOVA ${ }^{1,2}$, BODIL BJERKEHAGEN ${ }^{3}$, \\ INGVILD LOBMAIER $^{3}$ and SVERRE HEIM ${ }^{1,2,4}$
}

\author{
${ }^{1}$ Section for Cancer Cytogenetics, Institute for Cancer Genetics and Informatics, The Norwegian Radium Hospital, \\ Oslo University Hospital; ${ }^{2}$ Centre for Cancer Biomedicine, Faculty of Medicine, University of Oslo; ${ }^{3}$ Department of Pathology, \\ The Norwegian Radium Hospital, Oslo University Hospital; ${ }^{4}$ Faculty of Medicine, University of Oslo, Oslo, Norway
}

Received September 27, 2015; Accepted November 26, 2015

DOI: $10.3892 /$ ijo.2015.3310

\begin{abstract}
RNA-sequencing of a splenic hemangioma with the karyotype 45 47,XX,t(3;6)(q26;p21) showed that this translocation generated a chimeric TBLIXRl-HMGAl gene. This is the first time that this tumor has been subjected to genetic analysis, but the finding of an acquired clonal chromosome abnormality in cells cultured from the lesion and the presence of the TBLIXR1-HMGAl fusion in them strongly favor the conclusion that splenic hemangiomas are of a neoplastic nature. Genomic PCR confirmed the presence of the TBLIXR1-HMGAl fusion gene, and RT-PCR together with Sanger sequencing verified the presence of the fusion transcripts. The molecular consequences of the $t(3 ; 6)$ would be substantial. The cells carrying the translocation would retain only one functional copy of the wild-type TBLIXRI gene while the other, rearranged allele could produce a putative truncated form of TBL1XR1 protein containing the LiSH and F-box-like domains. In the TBLIXR1-HMGAl fusion transcript, furthermore, untranslated exons of $H M G A 1$ are replaced by the first 5 exons of the $T B L 1 X R 1$ gene. The result is that the entire coding region of $H M G A 1$ comes under the control of the $T B L 1 X R 1$ promoter, bringing about dysregulation of $H M G A 1$. This is reminiscent of similar pathogenetic mechanisms involving high mobility genes in benign connective tissue tumors such as lipomas and leiomyomas.
\end{abstract}

\section{Introduction}

Splenic hemangiomas, although infrequent, represent the most common benign neoplasms of the spleen with an incidence of

Correspondence to: Dr Ioannis Panagopoulos, Section for Cancer Cytogenetics, Institute for Cancer Genetics and Informatics, The Norwegian Radium Hospital, Oslo University Hospital, P.O. Box 4953 Nydalen, NO-0424 Oslo, Norway

E-mail: ioannis.panagopoulos@rr-research.no

Key words: splenic hemangioma, chromosomal translocation, fusion gene, RNA sequencing, chimeric TBL1XR1-HMGA1 gene
$0.03-14 \%$ found in large autopsy series $(1,2)$. In the vast majority of cases, splenic hemangiomas are incidental surgical, radiologic, or autopsy findings, made during evaluation for other disorders (1-3). Arber et al (3) reported 7 localized splenic hemangiomas all of which were discovered incidentally in surgical patients. In a large series of 32 patients with splenic hemangioma, only 6 presented with abdominal symptoms and only 4 had a palpable spleen (1).

Because of the general absence of presenting symptoms and the typically incidental nature of splenic hemangiomas, the age at presentation varies considerably. Several non-autopsy, surgical series revealed an average age at detection/presentation of between 51 and 63 years $(1,3)$. However, examination of autopsy data reveals a much younger average patient age (4) indicating that these benign lesions are likely to be present but remain undetected for long periods of time. No gender or race predilection has been reported (1).

Splenic hemangiomas are thought to be congenital in origin, arising from sinusoidal epithelium (5). Whether they are neoplastic or represent some other type of misgrowth, remains uncertain. They typically appear as circumscribed, non-encapsulated, honeycomb-like, red-purple masses that frequently blend imperceptibly into the surrounding splenic parenchyma (4). The spaces are composed of sponge-like tissue filled with blood and separated by fibrous septa. Occasional calcification may be seen, often in association with an organized infarct (6). Microscopically, the majority of hemangiomas are cavernous in nature, consisting of large interconnected, dilated, blood-filled spaces lined by a monolayer of cytologically bland endothelial cells separated by thin fibrous septa or splenic pulp tissue. Pure capillary architecture is less common. Instead, many lesions contain varying proportions of both cavernous and capillary components (4). Immunophenotypically, splenic hemangiomas show reactivity of endothelial lining cells for CD31, von Willebrand factor, Ulex europeaus, lectin I, and CD34. This pattern raises the possibility that splenic hemangioma may derive from a combination of splenic venous structures as well as from splenic sinusoidal cells (4).

Most splenic hemangiomas tend to be small in size $(<4 \mathrm{~cm})$ although lesions $\leq 36 \mathrm{~cm}$ have been reported (4). They need not be entirely without complications as larger lesions may 
rupture with resulting intra-abdominal hemorrhage (7-11). In some patients, they cause the Kasabach-Meritt syndrome (12).

The etiology and pathogenesis of splenic hemangiomas are unclear and no cytogenetic or molecular genetic information about the disease has been published. We here describe the cytogenetic analysis of a splenic hemangioma and the fusion gene corresponding to the chromosomal translocation thus found.

\section{Materials and methods}

Ethical approval. The study was approved by the Regional Committee for Medical and Health Research Ethics, SouthEast Norway (REK Sør) http://helseforskning.etikkom.no). Written informed consent was obtained from the patient. The consent included acceptance that the clinical details be published. The ethics committee's approval included a review of the consent procedure. All patient information has been anonymized and de-identified.

Patient. A twenty-nine-year-old woman was incidentally diagnosed with a splenic hemangioma during an ultrasound examination for cholecystitits. She had been without symptoms attributable to the splenic lesion, possibly except some pressure in the upper left abdomen. Because of continuous growth of the hemangioma, it was decided to do a splenectomy. Histological examination (Fig. 1) showed that the lesion was composed of large, blood-filled vessels lined by flat endothelium and separated by thin fibrous septa or splenic pulpa. Immunohistochemical analysis showed positivity for CD31 and ERG.

Control sample. The control sample was FirstChoice human spleen total RNA (Life Tehnologies, Carlsbad, CA, USA).

G-banding and karyotyping. Fresh tissue from a representative area of the tumor was received and analyzed cytogenetically as part of our diagnostic routine. The sample was disaggregated mechanically and enzymatically with collagenase II (Worthington, Freehold, NJ, USA). The resulting cells were cultured and harvested using standard techniques. Chromosome preparations were G-banded with Wright stain and examined. Peripheral blood lymphocytes stimulated with phytohemagglutinin (PHA) for $72 \mathrm{~h}$ were also karyotyped. The karyotypes were written according to the International System for Human Cytogenetic Nomenclature (ISCN) 2009 guidelines (13).

RNA and DNA extraction. Tumor tissue adjacent to that used for cytogenetic analysis and histologic examination had been frozen and stored at $-80^{\circ} \mathrm{C}$. Total RNA was extracted using miRNeasy Mini kit according to the manufacturer's instructions (Qiagen Nordic, Oslo, Norway). Tumor tissue was disrupted and homogenized in Qiazol Lysis Reagent (Qiagen) using a 5-mm stainless steel bead and TissueLyser II (Qiagen). Subsequently, total RNA was purified using QIAcube (Qiagen). The RNA quality was evaluated using the Experion Automated Electrophoresis system (Bio-Rad Laboratories, Oslo, Norway). The RNA quality indicator (RQI) was 9.0. Genomic DNA was extracted using the Maxwell 16 Instrument System and the Maxwell 16 Tissue DNA Purification kit (Promega, Madison, WI, USA), and the concentration and purity of DNA were measured using NanoVue Plus Spectrophotometer (GE Healthcare Life Sciences, Oslo, Norway).

High-throughput paired-end RNA-sequencing. Three micrograms of total RNA were sent for high-throughput paired-end RNA-sequencing at the Norwegian Sequencing Centre, Ullevål Hospital (http://www.sequencing.uio.no/). The RNA was sequenced using an Illumina HiSeq 2000 instrument and the Illumina software pipeline was used to process image data into raw sequencing data. The regular TruSeq library preparation protocol (http://support.illumina.com/downloads/ truseq_rna_sample_preparation_guide_15008136.ilmn) was used. The reads obtained had a length of 100 base pairs (bp). A total of 74 million reads were obtained. The quality of the raw sequence data was assessed using FastQC software (http://www.bioinformatics.babraham.ac.uk/projects/fastqc/). The software TopHat-Fusion was used for the discovery of fusion transcripts $(14,15)$. To verify further the fusion gene which was found by TopHat-Fusion, the 'grep' command (http://en.wikipedia.org/wiki/Grep) was used to search the fastq files of sequence data (http://en.wikipedia.org/wiki/ FASTQ_format). Our 'specific expression' was a sequence of 20 nucleotides at the fusion point, 10 bases upstream (5'-end gene), and 10 bases downstream from the junction ( 3 '-end gene). The expression was 'CGACCAATAGGTCCCCAAGT'. The sequences obtained by 'grep' were blasted against the human genomic plus transcript database (http://blast.ncbi. nlm.nih.gov/Blast.cgi) as well as the sequences with accession numbers NM_024665.4 (TBL1XRI) and NM_002131.3 (HMGAl) and DB051170.1 (TESTI2 Homo sapiens cDNA clone TESTI2040990, 5', mRNA sequence).

RT-PCR and genomic PCR analyses. The primers used for PCR amplification and Sanger sequencing are listed in Table I. For RT-PCR, $1 \mu \mathrm{g}$ of total RNA was reverse-transcribed in a 20- $\mu 1$ reaction volume using iScript Advanced cDNA Synthesis kit for RT-qPCR according to the manufacturer's instructions (Bio-Rad Laboratories). The $25 \mu \mathrm{l}$ PCR volume contained 12.5 $\mu$ 1 Premix Ex Taq ${ }^{\mathrm{TM}}$ DNA Polymerase Hot Start Version (Takara Bio Europe/SAS, Saint-Germain-en-Laye, France), $1 \mu \mathrm{l}$ of cDNA, and $0.4 \mu \mathrm{M}$ of each of the forward and reverse primer. The primer sets TBL1XR1-229F1/DB051170-Intr2R1 and TBL1XR1-229F1/HMGA1-324R1 were used to detect possible TBL1XR1-HMGAl fusion transcripts. The quality of the cDNA synthesis was examined by amplification of a cDNA fragment of the $A B L 1$ gene using the primers ABL1-91F1 and ABL1-404R1 (16).

For genomic PCR, the $25 \mu \mathrm{l}$ PCR volume contained $12.5 \mu \mathrm{l}$ Premix Ex Taq ${ }^{\mathrm{TM}}$ DNA Polymerase Hot Start Version, $100 \mathrm{ng}$ DNA, and $0.4 \mu \mathrm{M}$ of each of the forward and reverse primers TBL1XR1-intron4-F1 and DB051170-intr2R1.

The PCR amplifications were run on a C-1000 Thermal cycler (Bio-Rad Laboratories) with an initial denaturation at $94^{\circ} \mathrm{C}$ for $30 \mathrm{sec}$, followed by 35 cycles of $7 \mathrm{sec}$ at $98^{\circ} \mathrm{C}, 30 \mathrm{sec}$ at $55^{\circ} \mathrm{C}\left(58^{\circ} \mathrm{C}\right.$ for genomic PCR), $1 \mathrm{~min}$ at $72^{\circ} \mathrm{C}$, and a final extension for $5 \mathrm{~min}$ at $72^{\circ} \mathrm{C}$. For amplification of the ABL1 cDNA fragment, the PCR cycling was an initial denaturation at $94^{\circ} \mathrm{C}$ for $30 \mathrm{sec}$ followed by 35 cycles of $7 \mathrm{sec}$ at $98^{\circ} \mathrm{C}$ and $2 \mathrm{~min}$ at 


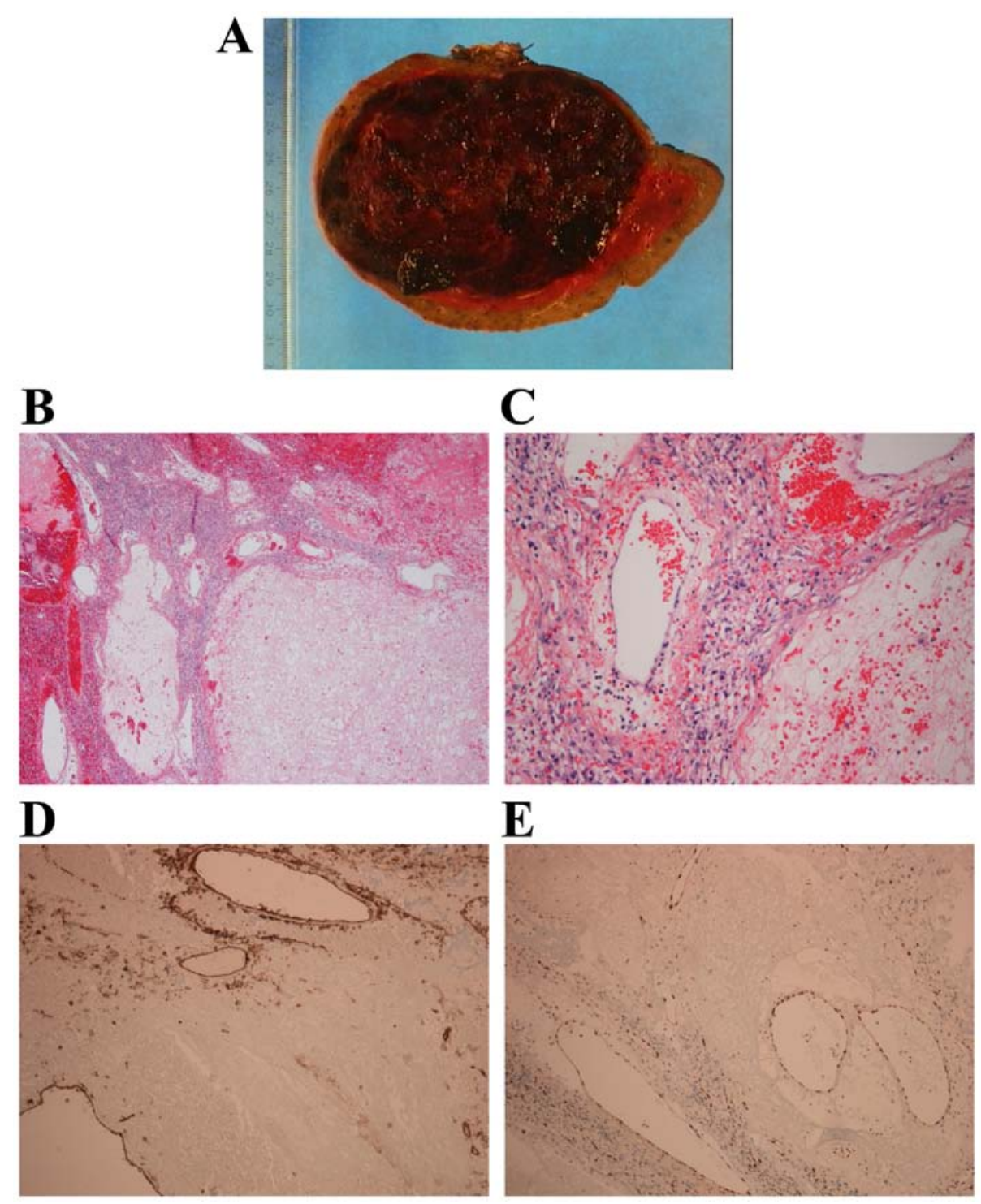

Figure 1. Pathologic examination of the splenic hemangioma. (A) Resected spleen with a well circumscribed hemangioma. (B and C) Microscopic image of splenic hemangioma with blood filled caverns with endothelial cell lining (H\&E staining). (D) The vessels are highlighted with CD31 staining. (E) The endothelial cell nuclei are highlighted with ERG staining.

Table I. Primers used for PCR amplification and Sanger sequencing analyses.

\begin{tabular}{|c|c|c|c|}
\hline Name & Sequence $\left(5^{\prime} \rightarrow 3^{\prime}\right)$ & Direction in PCR & $\begin{array}{l}\text { Position on Human Feb. } 2009 \\
\text { (GRCh37/hg19) Assembly }\end{array}$ \\
\hline TBL1XR1-229F1 & TGTTGTGACCTCATGGTTTAAGTGG & Forward & chr3:176,782,774-176,782,798 \\
\hline TBL1XR1-intron4-F1 & AAGCAGTCATTTCCAGTTGCTGC & Forward & chr3:176,769,680-176,769,702 \\
\hline HMGA1-324R1 & GGACTTCGAGCTCGACTCACTCA & Reverse & chr6:34,208,559-34,208,581 \\
\hline DB051170-Intr2R1 & GTACACCCAAGGGAGGCTTCATAC & Reverse & chr6:34,203,951-34,203,974 \\
\hline DB051170-Intr2R2 & TGATCAAGGTGGAGCCTTCCAGC & Reverse & chr6:34,204,001-34,204,023 \\
\hline ABL1-91F1 & CAGCGGCCAGTAGCATCTGACTTTG & Forward & chr9:133,729,459-133,729,483 \\
\hline ABL1-404R1 & CTCAGCAGATACTCAGCGGCATTGC & Reverse & chr9:133,730,335-133,730,359 \\
\hline
\end{tabular}

$68^{\circ} \mathrm{C}$, and a final extension for $5 \mathrm{~min}$ at $68^{\circ} \mathrm{C}$. Three microliters of the PCR products were stained with GelRed (Biotium, Hayward, CA, USA), analysed by electrophoresis through
$1.0 \%$ agarose gel, and photographed. The remaining $22 \mu \mathrm{l}$ PCR products were purified using the MinElute PCR purification kit (Qiagen Nordic) and sequenced at GATC Biotech 


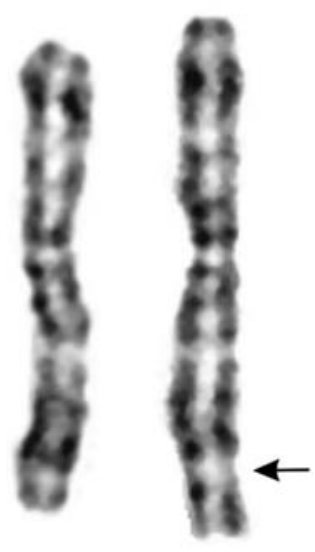

3 der(3)

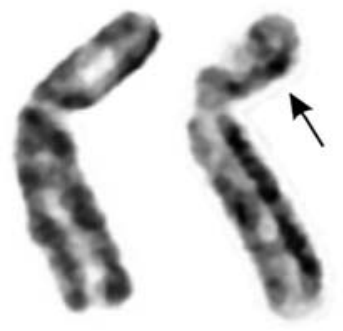

$6 \operatorname{der}(6)$

Figure 2. Partial karyotype showing the $\operatorname{der}(3) \mathrm{t}(3 ; 6)(\mathrm{q} 26 ; \mathrm{p} 21)$ and $\operatorname{der}(6) \mathrm{t}(3 ; 6)$ (q26;p21) together with the corresponding normal chromosome homologs; breakpoint positions are indicated by arrows.

(Germany, http://www.gatc-biotech.com/en/home.html). The BLAST software (http://blast.ncbi.nlm.nih.gov/Blast.cgi) was used for computer analysis of sequence data.

\section{Results}

G-banding. The G-banding analysis of the splenic hemangioma yielded a karyotype with a single clonal chromosome abnormality: 45 47,XX,t(3;6)(q26;p21)[cp22] (Fig. 2). The G-banding analysis of PHA-stimulated peripheral blood cells yielded a normal 46,XX karyotype. Thus, the translocation $\mathrm{t}(3 ; 6)(\mathrm{q} 26 ; \mathrm{p} 21)$ was found in cells of the splenic hemangioma only.

High-throughput paired-end RNA-sequencing analysis. Using the TopHat-Fusion on the raw sequencing data obtained by Norwegian Sequencing Centre, four fusions were found between chromosome bands 3q26 and 6p21 (Table II). Among them was a fusion between TBL1XR1 (from 3q26) and the sequence with accession number DB051170 which is an alternative splicing transcript of HMGAl found in testis (17).

In order to verify this fusion, we used the 'grep' command utility to search for expressions composed of 10 nt of TBLIXR1 and 10 nt of HMGAl upstream and downstream of the fusion point (Table III). Using the expression 'CGACCAATAGGTCCCCAAGT', which is composed of $10 \mathrm{nt}$, 'CGACCAATAG', from TBL1XR1 and $10 \mathrm{nt}$, 'GTCCCCAAGT', from HMGAl, 16 sequences were retrieved. BLAT of these sequences on the human genome browser-hg19 assembly (http://genome-euro.ucsc.edu/cgi-bin/hgGateway) showed that they were chimeric cDNA fragments composed of nucleotides which mapped on 3q26 in the coding region of TBL1XR1 and nucleotides mapped on chromosome band 6p21, circa 700 bp upstream of the $H M G A l$ sequence with accession number NM_002131 and within the sequence with accession number DB051170 which is an alternative splicing transcript of HMGAl found in testis (17). The fusion had occurred between nt 496 of TBLIXR1 mRNA reference sequence NM_024665.4 


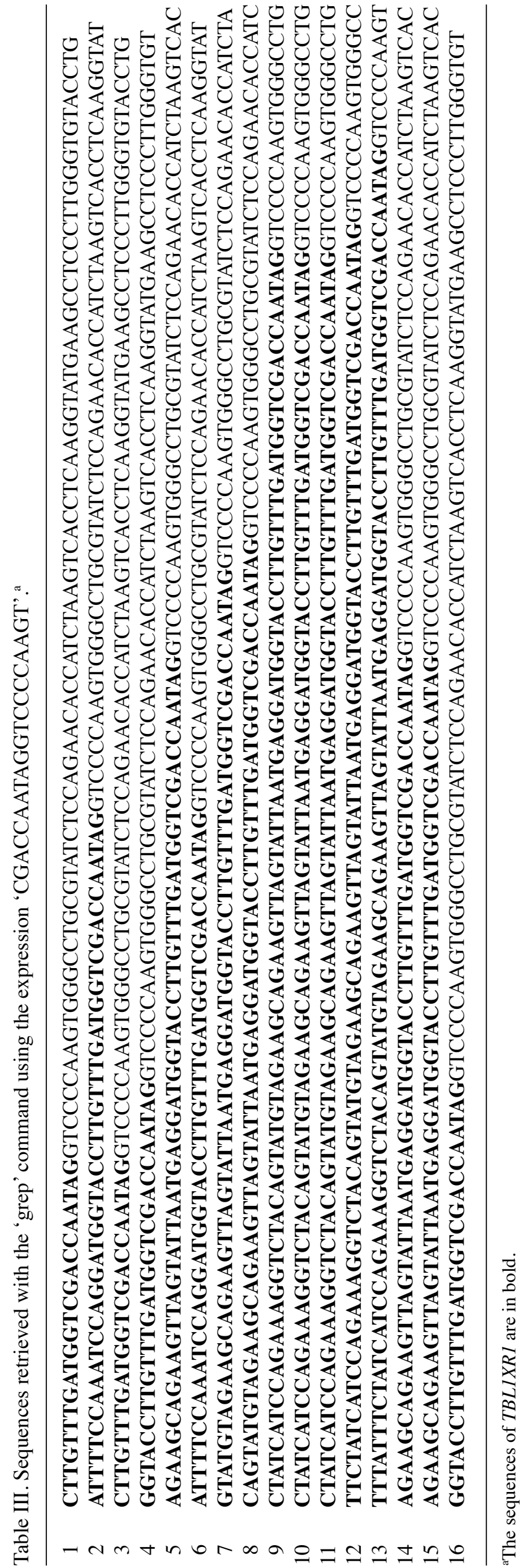

and nt 215 of the sequence with accession number DB051170.1 (Table III). We therefore decided to investigate the tumor further for the presence of the TBL1XR1-HMGA1 fusion transcript using molecular techniques. No other fusions were examined.

Molecular genetic confirmation of the TBLIXR1-HMGAI fusion. A 338-bp ABL1 cDNA fragment was amplified indicating the good quality of the synthesized cDNA (Fig. 3A).

To verify the data obtained with the RNA-sequencing/ TopHat-Fusion software and 'grep' command, PCR amplifications were performed using forward TBLIXRI and reverse $H M G A 1$ primers corresponding to sequences located upstream and downstream of the putative breakpoint, respectively. PCR with the two primer combinations, TBL1XR1-229F1/DB01170intr2R1 and TBL1XR1-229F1 and HMGA1-324R1, amplified fragments from the cDNA of splenic hemangioma but not from cDNA of the normal spleen. The results strongly suggested the presence of TBLIXR1-HMGA1 chimeric transcript in splenic hemangioma (Fig. 3A). Direct Sanger sequencing of the amplified fragments showed that both were TBLIXRI-HMGAI chimeric cDNA fragments with the fusion point identical to that found with TopHat-Fusion and the 'grep' command, i.e., the fusion had occurred between nt 496 of TBL1XR1 mRNA reference sequence NM_024665.4 and nt 215 of the sequence with accession number DB051170.1 (Fig. 3B).

Genomic PCR with the primer combination TBL1XR1intron4-F1/DB051170-intr2R1 amplified a fragment from the DNA of the splenic hemangioma. Direct Sanger sequencing showed that it was a genomic hybrid DNA fragment with sequences from the TBLIXRI and HMGAl genes (Fig. 4B). The junction point was identical to the fusion point found with TopHat-Fusion and the 'grep' command and with RT-PCR.

\section{Discussion}

We describe the first cytogenetic and molecular genetic analysis of a splenic hemangioma. The tumor had an acquired chromosomal translocation, $\mathrm{t}(3 ; 6)(\mathrm{q} 26 ; \mathrm{p} 21)$, which resulted in fusion of the TBLIXRI (from 3q26) and HMGAl (from $6 \mathrm{p} 21)$ genes. The fact that an acquired genetic aberration was found in the splenic hemangioma cells argues strongly that the disease is neoplastic.

The protein encoded by the TBLIXR1 gene has sequence similarity with members of the WD40 repeat-containing protein family (18). The WD40 group is a large family of proteins which appear to have a regulatory function (19-21). WD40 repeats mediate protein-protein interactions and members of the family are involved in signal transduction, RNA processing, gene regulation, vesicular trafficking, cytoskeletal assembly, and they may also play a role in the control of cytotypic differentiation (19-21). TBL1XR1 is a core component of $\mathrm{NCoR}$ (nuclear receptor corepressor) and SMRT (silencing mediator of retinoic acid and thyroid hormone receptors) repressor complexes and is essential in targeting SMRT/NCoR corepressor complexes to the promoter of target genes. It is also required for transcriptional activation by nuclear receptors and other regulated transcription factors (18). TBL1XR1 is further essential in the activation of Wnt- $\beta$ catenin and NF-кB signaling pathways (18). De novo deletions 

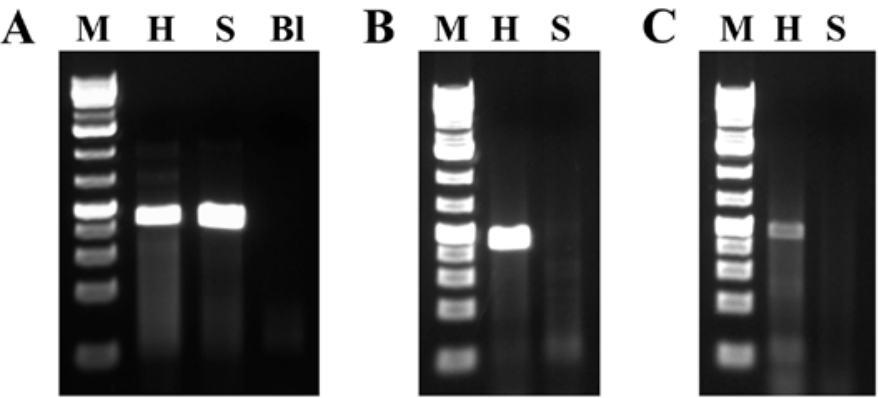

D

TBL1XR1 exon $5 \downarrow$ HMGA1 (DB051170)

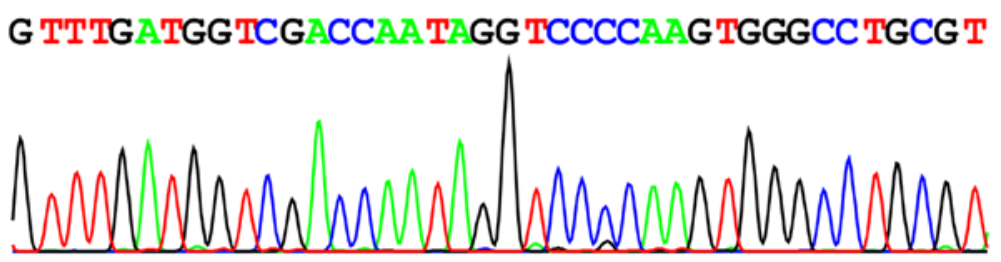

Figure 3. RT-PCR analyses of splenic hemangioma (H) together with normal spleen (S). (A) Amplification of an $A B L 1$ cDNA fragment using the primers ABL1-91F1 and ABL1-404R1. (B) Amplification of a cDNA fragment using the primers TBL1XR1-229F1 and DB051170-Intr2R1. (C) Amplification of a cDNA fragment using the primers TBL1XR1-229F1 and HMGA1-324R1. M, 1 kb DNA ladder (GeneRuler, Fermentas); B1, blank, water in cDNA synthesis. (D) Partial sequence chromatogram of the cDNA fragment showing the fusion (arrow) of TBL1XR1 with HMGA1 (sequence with accession number DB051170).

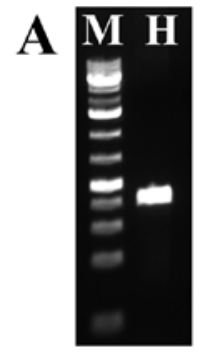

C

\section{B}

TBL1XR1-Intr4-F1

aagcagtcat ttccagttgc tgattgtagt ttctttattc cctccggact tcttatatga attcagaaag ttcctaaaa tgtttttta ggaacgaaga ttttcattc attctgatt ttgtataaat acaaataact ttaaatattg ccttgattt ttcttctctc acaatttcc aaatccagGA TGGTACCTTG TTTGATGGTC GACCAATAGg tccccaagtg ggcetgcgta tctccagaac accatctaag tcacctcaag gtatgaagcc tcccttgggt gtac

\section{DB051170-Intr2R1}

$\operatorname{chr} 3$ (q26.32)

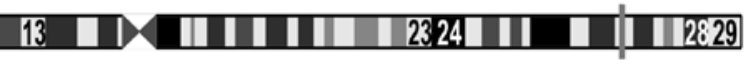

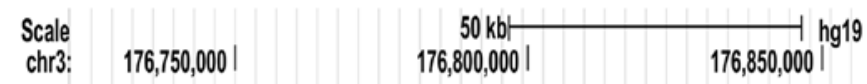

$176,900,0001$

RefSeq TBL1XR1

NM_024665.4 매

D

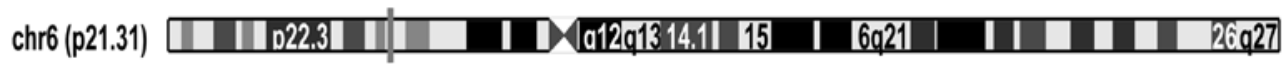

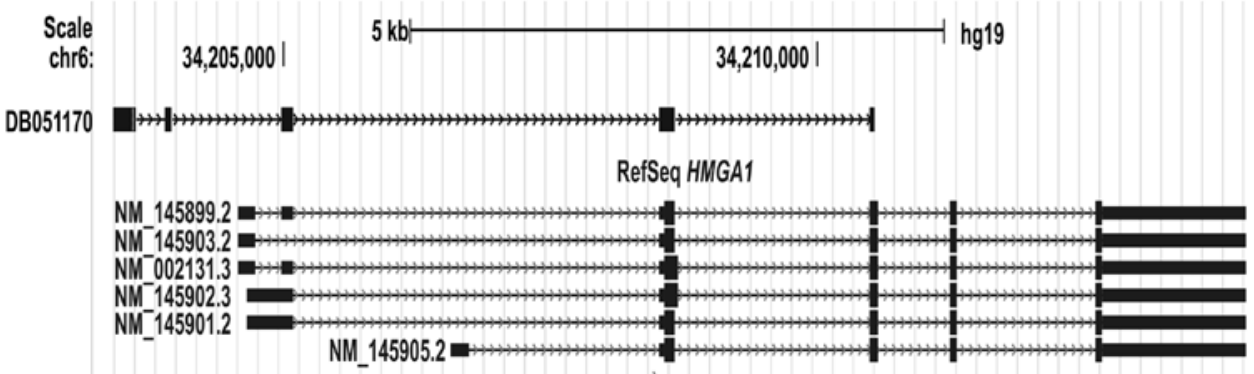

Figure 4. Genomic PCR analysis of splenic hemangioma (H). (A) Amplification of genomic DNA fragment using the primers TBL1XR1-intron4-F1 and DB051170-intr2R1. (B) Direct Sanger sequencing showed that the amplicon is a genomic hybrid DNA fragment with sequences from TBL1XR1 and HMGA1. The primers are shown in boxes. Arrow indicates the genomic breakpoint. Capital letters show part of exon 5 of TBL1XR1. (C) The TBL1XR1 gene. The location of TBLIXRI on chromosome 3 (vertical line) and the reference sequence NM_024665 are shown. (D) The HMGAl gene. The location of HMGAl on chromosome 6 (vertical line), the 6 reference sequences, and the sequence with the accession number DB051170 are shown. 
and recurrent mutations have been identified in the TBLIXRI gene and are linked to intellectual disability (18). TBLIXRI plays an important role in tumorigenesis, invasion, metastasis, and the development of therapy resistance (18). TBLIXRI is overexpressed in primary lung squamous cell carcinoma, breast cancer, cervical cancer, nasopharyngeal carcinoma, esophageal squamous cell carcinoma, and invasive prostate cancer (reviewed in ref. 18). Mutation of TBLIXRI was found in primary central nervous system lymphomas $(22,23)$. Deletions of $T B L 1 X R 1$ were described in $15 \%$ of ETV6-RUNX1 positive acute lymphoblastic leukemias (24). In frame TBLIXRI chimeric transcripts which code for chimeric proteins, were found in different neoplasias. A recurrent TBL1XR1-TP63 fusion gene was reported in diffuse large B-cell lymphoma, peripheral T-cell lymphoma, and follicular lymphoma which was the result of a chromosomal rearrangement between $3 q 26$ (TBL1XR1) and 3q28 (TP63) $(25,26)$. In most of the cases, the exons 1-7 of TBL1XR1 were fused in frame to exons 4-8 or 4-10 of TP63. Exon 14 or exon 4 of TBL1XR1 was involved in the remaining cases $(25,26)$.

$T B L 1 X R 1$ is fused to $R A R A$ in an acute promyelocytic leukemia carrying a variant $\mathrm{t}(3 ; 17)(\mathrm{q} 26 ; \mathrm{q} 21)$ translocation (27). The TBL1XR1-RARA fusion protein was predominantly localized in the nucleus, formed homodimers or heterodimers with retinoid $\mathrm{X}$ receptor $\alpha$, and acted as transcriptional activator in the presence of ligand. In the presence of pharmacologic doses of ATRA, TBLR1-RARA protein could be degraded, and its homodimerization was abrogated (27).

Fusions of $T B L 1 X R 1$ resulting in promoter swapping were also found $(28,29)$. In the breast carcinoma MCB7 cell line, the untranslated (5'-UTR) exon 1 of TBLIXR1 is fused with the start codon-bearing exon 2 of $R G S 17$, generating a fusion gene that encodes the full-length RGS17 protein under the control of TBL1XR1 gene promoter (28). The same 5'-UTR exon 1 of $T B L 1 X R 1$ was also found to be fused with the PIK3CA gene in breast cancer and prostate adenocarcinomas. The result was again the expression of $P I K 3 C A$ which came under the control of the TBLIXRI promoter (29).

The HMGAl gene encodes a non-histone protein involved in many cellular processes, including regulation of inducible gene transcription, integration of retroviruses into chromosomes, and the metastatic progression of cancer cells (30-32). The encoded protein preferentially binds to the minor groove of A+T-rich regions in double-stranded DNA. It has little secondary structure in solution but assumes distinct conformations when bound to substrates such as DNA or other proteins. The encoded protein is frequently acetylated and is found in the nucleus. Six transcript variants were identified encoding two different isoforms (http://www.ncbi.nlm.nih. gov/gene/3159). However, expressed sequence tags (EST) indicate that additional alternative splicing exists with various 5'-UTR sequences occurring in different tissues. For example, the EST with accession numbers DB051170 and DB03591 are found in testis, EST BM845429 in lymph node, CN350278 in embryonic stem cells, DC338100 in brain, and DA921912 is found in the small intestine. These splicing variants may be regulated by alternative promoters of $H M G A 1$ (17).

$H M G A 1$ is overexpressed in poorly differentiated cancers originating from all three germ layers, suggesting that it plays a fundamental role in tumorigenesis regardless of the cell type from which the tumor begins. High expression of the HMGAl gene or high levels of HMGA1 protein were found in cancers of the thyroid, lung, breast, bladder, prostate, colon, pancreas, uterine corpus, uterine cervix, kidney, head and neck, nervous system, stomach, liver, and hematopoietic system. Expression studies reveal that $H M G A 1$ overexpression correlates with adverse clinical outcomes in cancers (33-35).

The basis for $H M G A l$ overexpression is not well understood but it seems that $H M G A 1$ expression is induced through different pathways. For example, $H M G A l$ expression was shown to be induced by $\mathrm{cMYC}$ and AP1 transcription factors $(36,37)$. Recent studies suggest that microRNAs regulate HMGAl in some types of cancer (38-40). Another recent study showed that HMGA1 was an immediate target of the $\beta$-catenin/TCF-4 signaling pathway in colon cancer (41).

Dysregulation of HMGA1 as a result of specific chromosomal rearrangements involving chromosomal region $6 \mathrm{p} 21.3$ has also been identified in a variety of common benign mesenchymal tumors such as lipomas, uterine leiomyomas, endometrial polyps, and pulmonary hamartomas (42-51). The breakpoints in most tumors are located $3^{\prime}$ of $H M G A 1$, but $5^{\prime}$ or intragenic breakpoints have also been reported $(42,43,46,47)$. The findings we present indicate that a similar pathogenetic mechanism may be operative also in splenic hemangioma. Whether any systematic tumorigenic differences exist between this and the other benign neoplasias is a question that can be answered only after many more splenic hemangiomas are genetically analyzed.

So far, only one $H M G A l$-fusion transcript has been described in the literature: an HMGA1-LAMA4 found in a pulmonary hamartoma as a result of inv(6)(p21q21) (46). Fusion of HMGAl to the intergenic region between $L P P$ and TPRG1 in a lipoma carrying a $\mathrm{t}(3 ; 6)(\mathrm{q} 27 ; \mathrm{p} 21)$ has also been reported (52).

The present $\mathrm{t}(3 ; 6)(\mathrm{q} 26 ; \mathrm{p} 21)$ chromosomal rearrangement would have molecular consequences for both TBLIXRI and HMGA1. The TBLIXRl gene would have only a single functional copy of the gene left in the cell, while the other, rearranged allele would produce a putative truncated form of TBL1XR1 protein containing the LiSH and F-box-like domains (NP_078941; LiSH domain: 4-32, F-box-like domain: 41-86). Thus, the truncated form of TBL1XR1, through the LisH and F-box-like domains, could participate in protein dimerization, affect protein half-life, and could influence specific cellular localizations $(53,54)$.

With regard to $H M G A 1$, the TBLIXR1-HMGA1 fusion transcript leads untranslated exons of $H M G A 1$ to be replaced by the first 5 exons of the TBLIXRl gene. The result is that the entire coding region of $H M G A l$ comes under the control of the TBLIXRI promoter leading to dysregulation of $H M G A 1$.

\section{Acknowledgements}

This study was supported by grants from the Norwegian Radium Hospital Foundation.

\section{References}

1. Willcox TM, Speer RW, Schlinkert RT and Sarr MG: Hemangioma of the spleen: Presentation, diagnosis, and management. J Gastrointest Surg 4: 611-613, 2000. 
2. Husni EA: The clinical course of splenic hemangioma with emphasis on spontaneous rupture. Arch Surg 83: 681-688, 1961.

3. Arber DA, Strickler JG, Chen YY and Weiss LM: Splenic vascular tumors: A histologic, immunophenotypic, and virologic study. Am J Surg Pathol 21: 827-835, 1997.

4. Kutok JL and Fletcher CD: Splenic vascular tumors. Semin Diagn Pathol 20: 128-139, 2003.

5. Abbott RM, Levy AD, Aguilera NS, Gorospe L and Thompson WM: From the archives of the AFIP: primary vascular neoplasms of the spleen: radiologic-pathologic correlation. Radiographics 24: 1137-1163, 2004.

6. Halgrimson CG, Rustad DG and Zeligman BE: Calcified hemangioma of the spleen. JAMA 252: 2959-2960, 1984.

7. Kaplan J and McIntosh GS: Spontaneous rupture of a splenic vascular malformation. A report of three cases and review of the literature. J R Coll Surg Edinb 32: 346-347, 1987.

8. Rao RC, Ghose R, Sawhney S and Berry M: Hemangioma of spleen with spontaneous, extra-peritoneal rupture, with associated splenic tuberculosis - an unusual presentation. Australas Radiol 37: 100-101, 1993.

9. Pachl M, Elmalik K, Cohen M, Kamupira S, Walker J and Murthi G: Ruptured splenic cavernous hemangioma in a neonate. J Pediatr Surg 43: 407-409, 2008.

10. Carta G, D'Alfonso A, Nallbani A, Palermo P, Franchi V and Patacchiola F: Spontaneous rupture of splenic hemangioma in puerperium. Clin Exp Obstet Gynecol 39: 407-408, 2012.

11. Kang LY, Huang FD and Liu YY: Blunt abdominal injury with rupture of giant hepatic cavernous hemangioma and laceration of the spleen. Hepatobiliary Pancreat Dis Int 14: 109-110, 2015.

12. Hoeger PH, Helmke K and Winkler K: Chronic consumption coagulopathy due to an occult splenic haemangioma: KasabachMerritt syndrome. Eur J Pediatr 154: 365-368, 1995.

13. Schaffer LG, Slovak ML and Campbell LJ (eds): ISCN 2009 an International System for Human Cytogenetic Nomenclature. Karger, Basel, 2009.

14. Kim D, Pertea G, Trapnell C, Pimentel H, Kelley R and Salzberg SL: TopHat2: Accurate alignment of transcriptomes in the presence of insertions, deletions and gene fusions. Genome Biol 14: R36, 2013.

15. Kim D and Salzberg SL: TopHat-Fusion: An algorithm for discovery of novel fusion transcripts. Genome Biol 12: R72, 2011

16. Panagopoulos I, Gorunova L, Bjerkehagen B and Heim S: Fusion of the genes EWSR1 and PBX3 in retroperitoneal leiomyoma with $\mathrm{t}(9 ; 22)(\mathrm{q} 33 ; \mathrm{q} 12)$. PLoS One 10: $\mathrm{e} 0124288,2015$.

17. Kimura K, Wakamatsu A, Suzuki Y, Ota T, Nishikawa T, Yamashita R, Yamamoto J, Sekine M, Tsuritani K, Wakaguri H, et al: Diversification of transcriptional modulation: Largescale identification and characterization of putative alternative promoters of human genes. Genome Res 16: 55-65, 2006

18. Li JY, Daniels G, Wang J and Zhang X: TBL1XR1 in physiological and pathological states. Am J Clin Exp Urol 3: 13-23, 2015.

19. Xu C and Min J: Structure and function of WD40 domain proteins. Protein Cell 2: 202-214, 2011.

20. Li D and Roberts R: WD-repeat proteins: Structure characteristics, biological function, and their involvement in human diseases. Cell Mol Life Sci 58: 2085-2097, 2001

21. Neer EJ, Schmidt CJ, Nambudripad R and Smith TF: The ancient regulatory-protein family of WD-repeat proteins. Nature 371: 297-300, 1994

22. Nakamura T, Tateishi K, Niwa T, Matsushita Y, Tamura K, Kinoshita M, Tanaka K, Fukushima S, Takami H, Arita $\mathrm{H}$, et al: Recurrent mutations of CD79B and MYD88 are the hallmark of primary central nervous system lymphomas. Neuropathol Appl Neurobiol: Jun 25, 2015 (Epub ahead of print). doi: 10.1111/ nan.12259.

23. Gonzalez-Aguilar A, Idbaih A, Boisselier B, Habbita N, Rossetto M, Laurenge A, Bruno A, Jouvet A, Polivka M, Adam C, et al: Recurrent mutations of MYD88 and TBL1XR1 in primary central nervous system lymphomas. Clin Cancer Res 18: 5203-5211, 2012.

24. Parker H, An Q, Barber K, Case M, Davies T, Konn Z, Stewart A, Wright S, Griffiths M, Ross FM, et al: The complex genomic profile of ETV6-RUNX1 positive acute lymphoblastic leukemia highlights a recurrent deletion of TBL1XR1. Genes Chromosomes Cancer 47: 1118-1125, 2008.

25. Scott DW, Mungall KL, Ben-Neriah S, Rogic S, Morin RD, Slack GW, Tan KL, Chan FC, Lim RS, Connors JM, et al: TBL1XR1/TP63: A novel recurrent gene fusion in B-cell nonHodgkin lymphoma. Blood 119: 4949-4952, 2012.
26. Vasmatzis G, Johnson SH, Knudson RA, Ketterling RP Braggio E, Fonseca R, Viswanatha DS, Law ME, Kip NS, Ozsan N, et al: Genome-wide analysis reveals recurrent structural abnormalities of TP63 and other p53-related genes in peripheral T-cell lymphomas. Blood 120: 2280-2289, 2012.

27. Chen Y, Li S, Zhou C, Li C, Ru K, Rao Q, Xing H, Tian Z, Tang K, Mi Y, et al: TBLR1 fuses to retinoid acid receptor $\alpha$ in a variant $\mathrm{t}(3 ; 17)(\mathrm{q} 26 ; \mathrm{q} 21)$ translocation of acute promyelocytic leukemia. Blood 124: 936-945, 2014.

28. Hahn Y, Bera TK, Gehlhaus K, Kirsch IR, Pastan IH and Lee B Finding fusion genes resulting from chromosome rearrangement by analyzing the expressed sequence databases. Proc Natl Acad Sci USA 101: 13257-13261, 2004.

29. Stransky N, Cerami E, Schalm S, Kim JL and Lengauer C: The landscape of kinase fusions in cancer. Nat Commun 5: 4846 , 2014.

30. Benecke AG, Eilebrecht S, Benecke A and Eilebrecht S: RNA-mediated regulation of HMGA1 function. Biomolecules 5: 943-957, 2015

31. Reeves R and Beckerbauer L: HMGI/Y proteins: Flexible regulators of transcription and chromatin structure. Biochim Biophys Acta 1519: 13-29, 2001.

32. Resar LM: The high mobility group A1 gene: Transforming inflammatory signals into cancer? Cancer Res 70: 436-439, 2010.

33. Zhang Z, Wang Q, Chen F and Liu J: Elevated expression of HMGA1 correlates with the malignant status and prognosis of non-small cell lung cancer. Tumour Biol 36: 1213-1219, 2015.

34. Huang R, Huang D, Dai W and Yang F: Overexpression of HMGA 1 correlates with the malignant status and prognosis of breast cancer. Mol Cell Biochem 404: 251-257, 2015.

35. Liau SS, Rocha F, Matros E, Redston M and Whang E: High mobility group AT-hook 1 (HMGA1) is an independent prognostic factor and novel therapeutic target in pancreatic adenocarcinoma. Cancer 113: 302-314, 2008

36. Wood LJ, Mukherjee M, Dolde CE, Xu Y, Maher JF, Bunton TE, Williams JB and Resar LM: HMG-I/Y, a new c-Myc target gene and potential oncogene. Mol Cell Biol 20: 5490-5502, 2000.

37. Dhar A, Hu J, Reeves R, Resar LM and Colburn NH: Dominantnegative c-Jun (TAM67) target genes: HMGA1 is required for tumor promoter-induced transformation. Oncogene 23: 4466-4476, 2004.

38. Zhao XX, Yuan QZ, Mu DP, Sun DW, Bo QA, Pan GZ, Li GQ, Cui T, Ding PP, You FP, et al: MicroRNA-26a inhibits proliferation by targeting high mobility group AT-hook 1 in breast cancer. Int J Clin Exp Pathol 8: 368-373, 2015.

39. Liu K, Zhang C, Li T, Ding Y, Tu T, Zhou F, Qi W, Chen H and Sun X: Let-7a inhibits growth and migration of breast cancer cells by targeting HMGA1. Int J Oncol 46: 2526-2534, 2015.

40. Xu G, Wang J, Jia Y, Shen F, Han W and Kang Y: MiR-142-3p functions as a potential tumor suppressor in human osteosarcoma by targeting HMGA1. Cell Physiol Biochem 33: 1329-1339, 2014.

41. Bush BM, Brock AT, Deng JA, Nelson RA Jr and Sumter TF: The Wnt/ $\beta$-catenin/T-cell factor 4 pathway up-regulates highmobility group A1 expression in colon cancer. Cell Biochem Funct 31: 228-236, 2013.

42. Kazmierczak B, Bol S, Wanschura S, Bartnitzke S and Bullerdiek J: PAC clone containing the HMGI(Y) gene spans the breakpoint of a $6 \mathrm{p} 21$ translocation in a uterine leiomyoma cell line. Genes Chromosomes Cancer 17: 191-193, 1996.

43. Kazmierczak B, Wanschura S, Rommel B, Bartnitzke S and Bullerdiek J: Ten pulmonary chondroid hamartomas with chromosome 6p21 breakpoints within the HMG-I(Y) gene or its immediate surroundings. J Natl Cancer Inst 88: 1234-1236, 1996.

44. Dal Cin P, Wanschura S, Christiaens MR, Van den Berghe I, Moerman P, Polito P, Kazmierczak B, Bullerdiek J and Van den Berghe H: Hamartoma of the breast with involvement of $6 \mathrm{p} 21$ and rearrangement of HMGIY. Genes Chromosomes Cancer 20 90-92, 1997.

45. Williams AJ, Powell WL, Collins T and Morton CC: HMGI(Y) expression in human uterine leiomyomata. Involvement of another high-mobility group architectural factor in a benign neoplasm. Am J Pathol 150: 911-918, 1997.

46. Xiao S, Lux ML, Reeves R, Hudson TJ and Fletcher JA: HMGI(Y) activation by chromosome $6 \mathrm{p} 21$ rearrangements in multilineage mesenchymal cells from pulmonary hamartoma. Am J Pathol 150: 901-910, 1997.

47. Kazmierczak B, Dal Cin P, Wanschura S, Borrmann L, Fusco A Van den Berghe $\mathrm{H}$ and Bullerdiek J: HMGIY is the target of 6 p21.3 rearrangements in various benign mesenchymal tumors. Genes Chromosomes Cancer 23: 279-285, 1998. 
48. Kazmierczak B, Meyer-Bolte K, Tran KH, Wöckel W, Breightman I, Rosigkeit J, Bartnitzke S and Bullerdiek J: A high frequency of tumors with rearrangements of genes of the HMGI(Y) family in a series of 191 pulmonary chondroid hamartomas. Genes Chromosomes Cancer 26: 125-133, 1999.

49. Tallini G, Vanni R, Manfioletti G, Kazmierczak B, Faa G, Pauwels P, Bullerdiek J, Giancotti V, Van Den Berghe H and Dal Cin P: HMGI-C and HMGI(Y) immunoreactivity correlates with cytogenetic abnormalities in lipomas, pulmonary chondroid hamartomas, endometrial polyps, and uterine leiomyomas and is compatible with rearrangement of the HMGI-C and HMGI(Y) genes. Lab Invest 80: 359-369, 2000.

50. Medeiros F, Araujo AR, Erickson-Johnson MR, Kashyap PC, Dal Cin P, Nucci M, Wang X, Bell DA and Oliveira AM: HMGA1 and HMGA2 rearrangements in mass-forming endometriosis. Genes Chromosomes Cancer 49: 630-634, 2010.

51. Nezhad MH, Drieschner N, Helms S, Meyer A, Tadayyon M, Klemke M, Belge G, Bartnitzke S, Burchardt K, Frantzen C, et al 6 p21 rearrangements in uterine leiomyomas targeting HMGA1. Cancer Genet Cytogenet 203: 247-252, 2010.
52. Wang X, Zamolyi RQ, Zhang H, Pannain VL, Medeiros F, Erickson-Johnson M, Jenkins RB and Oliveira AM: Fusion of HMGA1 to the LPP/TPRG1 intergenic region in a lipoma identified by mapping paraffin-embedded tissues. Cancer Genet Cytogenet 196: 64-67, 2010.

53. Gerlitz G, Darhin E, Giorgio G, Franco B and Reiner O: Novel functional features of the Lis-H domain: Role in protein dimerization, half-life and cellular localization. Cell Cycle 4 : 1632-1640, 2005.

54. Mateja A, Cierpicki T, Paduch M, Derewenda ZS and Otlewski J: The dimerization mechanism of LIS1 and its implication for proteins containing the LisH motif. J Mol Biol 357: 621-631, 2006. 